\title{
Patrimonio, cultura y gobernanza urbana
}

\author{
Julia Rey Pérez | Dpto. de Historia, Teoría y Composición Arquitectónicas, Universidad de Sevilla
}

URL de la contribución <www.iaph.es/revistaph/index.php/revistaph/article/view/3877>

En el mes de septiembre de 2015 fue aprobada por la ONU la Agenda 2030 y los 17 Objetivos de Desarrollo Sostenible (SDG, por sus siglas en inglés). En concreto, el objetivo 11 propone "Hacer ciudades y asentamientos humanos inclusivos, seguros, resilientes y sostenibles" y, para ello, una de sus estrategias de trabajo es considerar el patrimonio y la cultura como ejes del desarrollo urbano sostenible.

En concreto esta idea es expresada en la meta 11.4 que invita a "Redoblar los esfuerzos para proteger y salvaguardar el patrimonio cultural y natural del mundo" (UNITED NATIONS, 2015: 22). Meses más tarde, en la conferencia de Hangzhou 2015 Culture and Sustainable Cities, desde la UNESCO se propone la Recomendación sobre el Paisaje Urbano Histórico (PUH) (UNESCO, 2011) como la herramienta clave para trabajar en la implementación de la Agenda 2030 desde la visión patrimonialista (UNESCO, 2015).

La propia definición de PUH incluida en la Recomendación deja bastante claro la consideración de la ciudad más allá, no solo del centro histórico, sino de los límites urbanos al señalar la importancia del contexto geográfico. Igualmente se mencionan las múltiples capas de información que a lo largo de la historia han ido conformando y determinando los rasgos del sitio, desde la topografía y las características naturales, así como todo lo relacionado con el medio urbanizado y las infraestructuras, los usos y la organización espacial, las relaciones visuales, los procesos económicos y los aspectos inmateriales vinculados con la diversidad y la identidad (UNESCO, 2011: 4).

Dicha Recomendación nace en un momento histórico donde el desarrollo urbano y la conservación del patrimonio urbano parecen estar enfrentados, más que considerarse como dos conceptos que tradicionalmente han ido de la mano. En este sentido el documento busca integrar este enfoque del PUH a la gestión urbana (HUL, 2016: 5), apoyándose en el hecho de que la globalización construye ciudades similares en términos financieros o de desarrollo urbano, sin embargo, "la cultura y el patrimonio son los recursos que siempre distinguirán unas ciudades de otras" (HUL, 2016: 6).

Todas estas cuestiones fueron ampliamente discutidas en la Conferencia de las Naciones Unidas sobre la Vivienda y el Desarrollo Urbano Sostenible (Hábitat III) que tuvo lugar en octubre de 2016 en Quito, Ecuador. En dicha conferencia se debatió intensamente acerca del reto que supone enfrentarse al desarrollo urbano previsto en los próximos 30 años, donde como aspecto innovador se incorpora el patrimonio y la cultura como una estrategia más en este desafío mundial. Con el compromiso intergubernamental, se aprobó la Nueva Agenda Urbana, donde se han incorporado todas las cuestiones planteadas anteriormente (UNITED NATIONS, 2016).

Con esta nueva perspectiva de crecimiento urbano donde se prevé que en un periodo de 30 años el $70 \%$ de la población mundial se concentre en ciudades (UNESCO, 2016; UNITED NATIONS, 2015), la cultura y el patrimonio no tienen otra opción más que incorporarse de forma protagonista a la elaboración de planes estratégicos de desarrollo urbano, económico y social. En este sentido, los conceptos o ideas que han sido puestos sobre la mesa de forma más intensa en la Conferencia Hábitat III han sido aquellos relacionados con cuestiones como la gobernanza urbana, la interdisciplinaridad y la participación ciudadana, debates que por otro lado, brillan por su ausencia en la mayoría de gobiernos locales o de equipos redactores de planes urbanos.

En la línea de esta propuesta, la Recomendación sobre el PUH propone 6 pasos para su aplicación: 1) Mapeo de recursos naturales, culturales y humanos; 2) Consenso en qué proteger: valores y atributos; 3) Evaluación de la vulnerabilidad al cambio y desarrollo; 4) Integración de los puntos anteriores en el marco del desarrollo urbano; 5) Dar prioridad a las acciones para la conservación y el desarrollo; y 6) Establecer asociaciones locales y los marcos de gestión (UNESCO, 2011: 3). Asimismo, desde la UNESCO se proponen 4 categorías de 


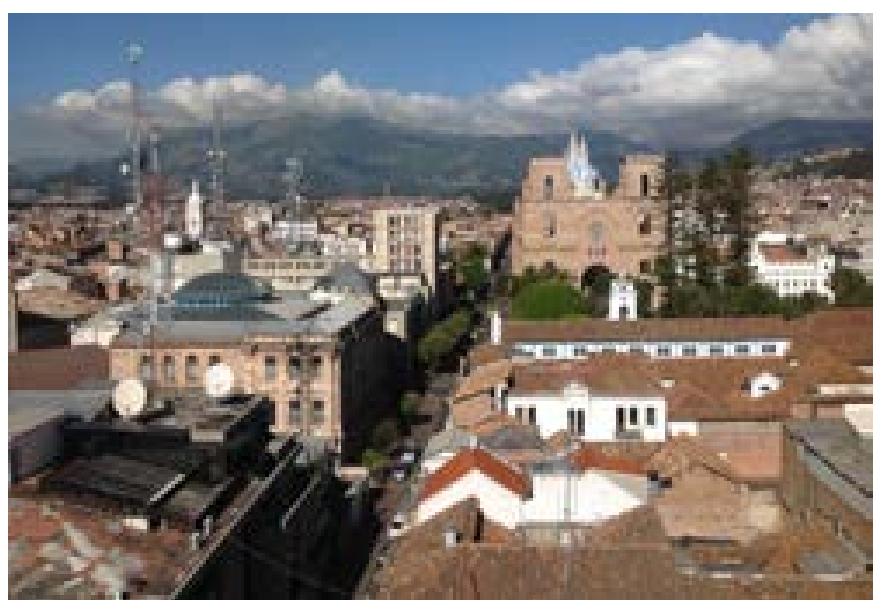

Centro histórico de Cuenca, Ecuador | foto Julia Rey

herramientas de trabajo para poner en marcha el enfoque de la Recomendación en cada localidad en función de su contexto: 1) Conocimiento y planificación; 2) Compromiso ciudadano; 3) Sistemas regulatorios; y 4) Financiación (HUL 2016: 15). Estos pasos y herramientas elaborados para la implementación de la Recomendación muestran claramente la intención de la UNESCO de vincular el patrimonio con cuestiones como la gobernanza urbana, la interdisciplinaridad y la participación ciudadana.

La realidad es que ahora la visión patrimonialista no se limita a académicos, investigadores o técnicos interesados en el patrimonio. La situación socioeconómica, cultural y política actual demanda un cambio de los actores implicados en la gestión de la ciudad, en la que se incluyen autoridades locales, gobiernos oficiales, técnicos que trabajan en el campo de la conservación urbana y el desarrollo urbano, investigadores, ciudadanos y universidades. El reto está puesto encima de la mesa, demandándose un papel activo del patrimonio y de la cultura que vaya de la mano de la preservación de la calidad de la vida urbana, de la protección de las identidades urbanas, de la valoración de las culturas locales y, por supuesto, del desarrollo social y económico sostenible.

Las preguntas son: ¿están preparadas nuestras instituciones andaluzas para asumir la Nueva Agenda Urbana y los SDG de la Agenda 2030? ¿existe una conciencia de evolución desde la gobernabilidad hacia la gobernanza a la hora de gestionar la evolución del desarrollo urbano? y, lo más importante, ¿es posible la aplicación de la Recomendación sobre el PUH tomando como punto de arranque la consideración de la cultura y el patrimonio como el eje vertebrador del desarrollo urbano? Realmente el desafío es tan simple como utilizar dicha Recomendación para elaborar el plan estratégico de cualquier ciudad, pueblo o incluso barrio, sin embargo la cuestión no es saber si estamos preparados para apostar por la interdisciplinariedad y la gobernanza urbana a través de dicho documento, sino saber si realmente queremos hacerlo.

\section{BIBLIOGRAFÍA}

- HUL (2016) (The Historic Urban Landscape) The hul guidebook. Managing heritage in dynamic and constantly changing urban environments. A practical guide to UNESCO's Recommendation on the Historic Urban Landscape <http://historicurbanlandscape.com/themes/196/userfiles/ download/2016/6/7/wirey5prpznidqx.pdf> [Consulta: 31/01/20 17]

- UNESCO (2011) Recommendation on the Historic Urban Landscape, Including a Glossary of Definitions. <http:// portal.unesco.org/en/ev.php-URL_ID=48857\&URL_DO=DO_ TOPIC\&URL_SECTION=201.html> [Consulta: 31/01/2017]

- UNESCO (2015) Hangzhou Outcomes. International Conference 'Culture for Sustainable Cities' <http://www. unesco.org/new/en/culture/themes/culture-and-development/ culture-for-sustainable-cities/> [Consulta: 31/01/2017]

- UNESCO (2016) Culture Urban Future. Global Report on Culture for Sustainable Urban Development. Unesco: París,2016 <http://unesdoc.unesco.org/images/0024/002462/246291E. pdf> [Consulta: 31/01/2017]

- UNITED NATIONS (2015) Transforming Our World: The 2030 Agenda for Sustainable Development (A/RES/70/1) <https:// sustainabledevelopment.un.org/post2015/transformingourwo rld/publication> [Consulta: 31/01/2017] 